\title{
Review of English for Ethiopia Grade 5 Textbook
}

\author{
Addis Kebede \\ Psychology Department, Bule Hora University College of Behavioral and Education Sciences, Adolla Wayyu, Ethiopia \\ Email address: \\ addisk567@gmail.com

\section{To cite this article:} \\ Addis Kebede. Review of English for Ethiopia Grade 5 Textbook. International Journal of Psychological and Brain Sciences. \\ Vol. 5, No. 3, 2020, pp. 40-46. doi: 10.11648/j.ijpbs.20200503.11
}

Received: May 25, 2020; Accepted: June 18, 2020; Published: July 28, 2020

\begin{abstract}
Constructivism is considered as leading paradigm of Ethiopian educational policy. So, instructional approaches and preparation of teaching materials expected to be in line with this paradigm. In this regard, educational psychologists, expected to review and comment on the qualities of instructional approaches used in textbooks. Accordingly, the present study aimed to investigate if English for Ethiopia grade 5 textbook is prepared in line with basic principles of constructivism theory. To this end, qualitative approach is used to review English for Ethiopia grade 5 textbook. In the present review course syllabus of English for Ethiopia grade 5 textbook and the teacher's guidebook is considered simultaneously with the textbook. The instrument used for the review developed by the present researcher and its' validity checked by three educational psychologists. The result of the review show that, except few limitations, English textbook used to teach Ethiopian grade 5 students is prepared in line with major principles of constructivism. The contents and structure of English for Ethiopia grade 5 textbook is good in terms of promoting personal construction of knowledge, enhancing active learning, encouraging collaborative learning, making learning realistic, make learning situations relevant, activate learners' prior knowledge, incorporating different concepts from different disciplines, integrating the four macro-language skills, and incorporating activities which have feature of enhancing learners' critical thinking, creative thinking and problem solving skills. Even though majority of tasks in English for Ethiopia grade 5 textbook are designed in line with constructivism principles, the textbook has limitations, in terms of allowing learners to form topics, incorporating self-assessment questions, allocating proportional time for units and incorporating activities which encourage use of authentic learning materials.
\end{abstract}

Keywords: Constructivism, Textbook Review, Active Learning

\section{Introduction}

The central theme of constructivism theory emphasizes on trusting learners' capacity in actively organizing and constructing knowledge [1]. According to constructivism paradigm, knowledge is constructed by the learner; most of the time previous knowledge of the child serves as a basis for construction of new knowledge [1]-[3]. Knowledge is not constructed by passively receiving, rather it requires active involvement of the learner [4]. According to constructivism theory child's active construction of knowledge takes place within a particular social and cultural context [5]. Consequently, constructivists believe that knowledge is constructed through personal interpretation of facts from multiple perspectives and context [6, 7]. Constructivism theory mainly emphasis learners' potential in constructing knowledge rather than merely recording knowledge [8]. In constructivist classrooms, learners actively engage in forming the topic they learn, rather than simply receiving what teachers taught in classrooms [9]. Accordingly, in constructivist classroom students take central role in language classrooms and teachers play role of facilitation, guiding, coaching, monitoring and scaffolding [10].

Constructivism learning theory has four characteristics [11]. The first characteristics of constructivism theory is that learners construct knowledge that makes sense to them. Learners have capacity to build their knowledge rather than simply receiving. The second characteristics is that new learning depends on current understanding. Learners acquisition of new knowledge depends on current knowledge they have. Hence, in EFL texts before introducing new concepts present pre-reading activities that activate learners' prior knowledge plays crucial role in enhancing effectiveness of EFL reading classrooms. The third characteristics is that social interaction facilitates learning. Children knowledge 
constructions significantly affected by interaction they have with their peers, teachers, families and other community members and media. The forth characteristics is that meaningful learning occurs within real-world tasks. Realworld tasks mainly rely on use of authentic materials and tasks. In language education authentic materials refers to newspapers, magazines, articles, songs, web pages, radio \& TV broadcasts, films, leaflets, flyers, posters, etc. [12]. Accordingly, tasks relay on those materials will make the classrooms authentic. Constructivists believe that exposure to authentic reading materials motivate learners for further reading [13]. Having habit of reading different texts written in English help learners to be fluent in using the language for various purposes. Not only this, it also increases their confidence level. When the learners got exposure for authentic materials, they develop feeling that they are learning real language [12]. Additionally, in language classrooms, constructivists suggest idea of learning by doing [14]. When children deal with real world problems, rather than abstract ideas, their critical thinking and problemsolving skills will be nurtured. Thus, EFL textbooks expected to ask teachers and/or students manipulation of authentic materials and present activities which require reading those materials.

Constructivism theory stresses on importance of creating favorable conditions for critical thinking, flexibility, creative thinking, active learning and collaboration $[15,16]$. Critical thinking can be encouraged when lessons and subjects: begin with questions, create foundations i.e., provide students review of related information, consult the classics, include contents which help students to have interdisciplinary knowledge, utilize peer groups, provide sequential activities, prepare goal free problems/activities, facilitate roleplaying, translate thoughts to pictures, prioritize critical thinking and change misconceptions [17]. According to Constructivism theory, in teaching English as a foreign language incorporating different and large contents will span opportunity of using different aspects of the language for various purposes [18].

When preparing a language textbook, it need to: be free from stereotypical images and messages; incorporate fun elements; and allocate sufficient and proportional time for every lesson based on the contents. Textbook pictures have impact on language learning process, because, most of the time students tend to see picture before they begin reading a passage [19]. Due to this, it is assumed that thought of students improved with the presence of carefully incorporated pictures in a textbook. Additionally, images in a textbook have potential of motivating students to read passages presented with them; especially, when they have features representing of real life conditions. Therefore, well produced pictures and the general feature the textbook make reading attractive and cheerful [19]. Regarding allocate sufficient and proportional time for lessons in a textbook, study conducted by [20] showed that allocating insufficient learning time have a direct negative effect on EFL achievement. So, authors of EFL textbooks need to be logical and systematic in seating time required to teach each lesson in the book.

Regarding, issues related to avoiding stereotypical images and messages in language textbooks, Hamilton and Associates as cited in [21] warned that:

..."stereotyped portrayals of the sexes and underrepresentation of female characters contribute negatively to children development, limit their career aspirations, frame their attitudes about their future roles as parents, and even influence their personality characteristics".

Attitudes towards other persons' race, ethnicity, gender, social class, or age may be influenced by latent content of textbooks [22]. The same author stated that, when students use the textbook for longer time, its' impact on students' attitude increases. On the other hand, when a textbook incorporates cultural elements of native speakers, it helps students to construct images of the places where the language is spoken; and helps them to forecast the key aspects the language [23]. Unless students know culture of people who speak the target language or the country in which it is spoken, taught of the language become meaningless. Meaning, in L2 classrooms, in line with teaching important language skills, it is also, important to aware students about culture of native speakers. Therefore, students will develop actual language skill of using the language [24]. Additionally, EFL textbook need to incorporate well-known characters from different areas of the world. When textbooks incorporate well-known characters from different areas of the world they may grasp the six teachable pillars of character": trustworthiness, respect, responsibility, fairness, caring and citizenship [25].

Constructivists promote about making learning fun and enjoyable [16]. Fun elements have nature of motivating and energizing students for learning [26]. Learning requires repetition and commitment. So, EFL textbooks need to incorporate fun elements because as far as students attracted to the elements of the passages they will read the text repeatedly. With repeated reading and practicing different aspects of the language, students will improve their language fluency. In addition to the contents in the textbook, interaction and using variety of learning materials contributes the process of making EFL learning attractive. Meaning, interaction allow learners active engagement and collaboration between them [26]. The interaction process and collaboration between pupils makes EFL learning easy and enjoyable. Again, use of variety of learning materials make EFL learning enjoyable and attractive [26]. It about incorporating materials such as newspaper, articles, audio, texts, role play activities, films, music, educational games, group work, experiments, field trips, guest speakers, and quiz games, challenging students by giving them different activities such as riddles, problem solving exercises and reading comprehension questions which require critical thinking.

Regarding EFL competency expected from grade 5 students, language instruction during middle and upper elementary language classrooms mainly focus on 
development of comprehension skills with other aspects of language which assist mastery of language comprehension [27]. Incorporating different language teaching strategies will help students to think aloud about strategy they should employ for understanding and sharing different language learning strategies among themselves [28]. Discussion between small group of students help students to develop different aspects of English language skill. In the meantime, students get opportunity to interact and practice different aspects of English language through reflecting and discussing on different activities found in EFL textbooks.

Thus, the present study is review of English for Ethiopia grade 5 textbook. The present review mainly focuses on checking whether or not English for Ethiopia grade 5 textbook focused on teaching comprehension skill, fluent word recognition and vocabulary knowledge in line with basic principles of constructivism theory.

\section{Statement of the Problem}

Constructivism is assumed as leading paradigm of current Ethiopian education in general and EFL education specifically. Consequently, preparation of teaching materials and approaches used in EFL classrooms expected to be in line with basic principles of constructivism theory. [16] argue that in preparing language textbooks, supporters of constructivism theory suggests to mainly emphasize on: personal construction of knowledge, associating prior knowledge with new information, personal interpretation of experience, realistic and relevant learning situations, use of authentic learning materials, multiple exploration of knowledge, meaning making, problem solving, critical thinking, creative thinking, active learning and collaboration.

Since, constructivism is considered as leading paradigm of instructional approaches in Ethiopia, reviewing English for Ethiopia grade 5 textbook in light with major principles of constructivism seems feasible. Hence, from literature review made the present researcher reviewed the textbook to check if the lessons in Ethiopia grade 5 textbook: promotes personal construction of knowledge, active learning and collaboration; emphasizes on realistic, relevant learning situations and learners' prior knowledge; encourages multiple exploration of knowledge and meaning making; supports personal interpretation of experience and use of authentic learning materials; and, enhances critical thinking, creative thinking and problem solving skills.

\section{Objective of the Study}

The present study aimed to investigate English for Ethiopia grade 5 student textbook, to check its preparation in line with basic principles of constructivism theory.

\section{Limitation of the Study}

The present review limited on English for Ethiopia grade 5 student textbook only. Additionally, the review limited on checking the preparation of Ethiopia grade 5 student textbook in line with constructivism principles and did not address difficulty level of lessons.

\section{Methodology}

This review is made to analyze whether or not preparation of English for Ethiopia grade 5 student textbook is in line with basic principles of constructivism theory. Descriptive qualitative approach is used to review this textbook. In the review course syllabus of English for Ethiopia grade 5 textbook and the teacher's guidebook is considered simultaneously with the textbook. The instrument used for the review developed by the present researcher. The validity of instrument used for the review is checked by one psychology professor and two educational psychology $\mathrm{PhD}$ candidates. The instruments modified based on suggestion and comments provided by the professor and the $\mathrm{PhD}$ candidates.

\section{Findings and Discussion}

In this section of the study following introduction about the general scheme of the English for Ethiopia grade 5 textbook, findings are presented by discussing with the existing literature under five major themes.

English for Ethiopia grade 5 textbook has 12 units in general; in each unit there are: listening and speaking lessons, reading lessons and writing lessons. Each unit begins with objectives written in general terms. The textbook under review incorporated about 16 reading passages; 4 poems; 9 dialogues; 12 revision exercises; 2 revision units one at the end of each semester; a number of: pre-reading and postreading activities and exercises, grammar highlights, guided compositions, and vocabularies attached as appendix. While reviewing this textbook the course syllabus and the teacher's guide prepared for this subject also considered simultaneously.

\subsection{Promoting Personal Construction of Knowledge, Active Learning and Collaboration}

The directions stated on English for Ethiopia grade 5 course syllabus and the teacher's guidebook emphasizes on encouraging learners' personal construction of knowledge, student centeredness and collaborative learning. The course syllabus and the guidebook suggest grade 5 English language teachers to play role of facilitator, guider and coach. The guidebook also suggests teachers to implement different types of active learning approaches which help learners to develop independent knowledge construction, teamwork and social skills. Hence, regarding role of EFL teachers, the course syllabus and the guidebook is congruent with the principle of constructivism which focuses on making learners main actor of knowledge construction and suggest teachers to play role of facilitator, guide, coach, monitor and scaffolding learning activities, rather than teachers acting as mere knowledge transmitters [10]. Similarly, except some 
limitations, grade 5 English textbook for Ethiopia is congruent with principles of constructivism in promoting personal construction of knowledge, active learning and collaboration. Constructivists emphasis on activities which enhance learners' metacognition, self-analysis, selfregulation, self-reflection, and self-awareness of students [29]. All these elements, highly contributes for learners' independent knowledge construction, active engagement and collaboration. In this regard, the textbook under review incorporated a number of individual, pair and small group tasks which contribute for learners' collaboration, metacognition, self-analysis, self-regulation, self-reflection and self-awareness. Individual, pair and group activities incorporated in the textbook under review allow learners: independent knowledge construction; reflect their ideas through presenting individual, pair and group work; and, selfevaluation. As students receive feedback from the teachers and their peers they evaluate themselves and correct their mistakes. On the other hand, despite incorporating a number of activities which promotes personal construction of knowledge, active learning and collaboration, the textbook under review did not incorporate adequate self-assessment questions. Presenting self-assessment questions with answer keys have possibility of fostering sprit of independent learning. Because independent can be promoted through presenting self-assessment questions. Self-assessment questions help students to know about their own strength and weaknesses. Hence, it is possible to say that English for Ethiopia grade 5 textbook provides limited opportunity for self-analysis, self-regulation and self-awareness.

Constructivists promote active learning through engaging learners in forming the topics they learn, rather than simply receiving what teachers teach in classrooms [11]. In this regard, even though, the objectives stated at the beginning of each learning unit are written in general terms, the textbook is full of instructions and specific objectives. The lesson objectives stated in the textbook under review did not provide any space to consult and engage learners in forming topics.

\subsection{Emphasizing on Realistic, Relevant Learning Situations and Learners' Prior Knowledge}

Congruent to [27] suggestion about the focus of literacy instruction at the middle age, the textbook under review incorporated a number of reading paragraphs and exercises which is helpful for students in developing comprehension, word recognition and vocabulary skills. Literacy instruction during middle age expected to focus on teaching comprehension, word recognition skill and vocabulary skill [27]. The textbook also incorporated majority of comprehension strategies suggested by [28] such as introducing, connecting to prior knowledge, generating mental images about text meaning, asking questions, seeking clarification when confused, and summarizing to be practiced in small group of readers. These elements make the textbook under review realistic and relevant regarding teaching English language competency need to teach grade 5 students.
The textbook under review is congruent with constructivists principle in creating relevant learning situations. According to constructivists, well produced pictures in a textbook and features of the textbook made reading attractive and cheerful [19]. Congruent with this principle of constructivism, the font size and space between vertical lines of passages are good, majority of images in the textbook show real life of peoples and they are functional. The textbook under review is congruent with constructivists suggestion in making contents of textbook free from stereotyped information related to gender, equal representation of female and free from stereotypical information related to race, ethnicity, gender, social class and age $[21,22]$. Images the textbook under review represent characters of male and female proportionally. And also, name of males and females used in the textbook under review are proportional. Moreover, the textbook is free from stereotypical information related to race, occupations, age groups and social groups. In general, the latent contents of the textbook under review positively contributes in creating relevant learning situation.

Regarding allocating proportional time for lessons, English for Ethiopia grade 5 course syllabus has some limitations. The course syllabus of textbook under review did not allocate proportional time for lessons in the textbook. This has adverse effect on creating relevant learning situation. The syllabus, uniformly gave 13 periods for each unit (the book has 12 units in general) found in the textbook without differentiating time needed across chapters and variation of learning tasks. This shows some units may use extended time, whereas units with wide contents may not get enough time, unless the teacher systematically modify the time indicated on the course syllabus. In this regard, research findings revealed that allocating insufficient learning time have a direct negative effect on language learning [20].

\subsection{Encouraging Multiple Exploration of Knowledge and Meaning Making}

According constructivists, integrating contents from different disciplines in English language education allow students to develop skill of exploring knowledge from multiple sources and develop effective meaning making skill $[18,29]$. Congruent with this principle of constructivism, the textbook under review addressed different concepts from different disciplines. The authors of the textbook under review tried to address different concepts from different fields about time management, morality, nature, science, health, literature and geography as major lessons of the subject in teaching the four macro-language skills. These lessons provide opportunity of developing interdisciplinary knowledge and meaning making skill from multiple perspectives.

Additionally, congruent to constructivism assumption, English for Ethiopia grade 5 textbook prepared by integrating the four macro-language skills. In this regard, scholars argue that whether to integrate the four language skills i.e., listening, speaking, reading and writing all together in a 
single language textbook or teach them separately. Scholars like [30] argue that, integration of the four language skills in a single textbook have limitations. According to this scholar, integrating the four language skills lacks concentration needed for a single language skill, it requires well-trained teacher and it is difficult to support students with different abilities of the four language skills. In contrary to this argument, constructivism theory stresses on knowledge construction from multiple perspectives $[4,31]$ and teaching language by incorporating different and large content will span opportunity of using the language for various types of communications [18]. These assumptions of constructivism have implication for teaching the four language skills in an integrated manner. In this regard, grade 5 English textbook for Ethiopia is congruent with the assumptions of constructivists principle. It is prepared by integrating the four language skills in each unit. Integrating the four language skills in a single textbook allow students to have sociocultural communicative competence in line with developing learners' fluency and accuracy and language skills have also nature of feeding each other.

On the other hand, though the textbook under review integrated many elements which allow learners multiple exploration of knowledge and meaning making, it has gap in incorporating cultural elements from different parts of the world. Constructivists believe that cultural elements support learners' multiple exploration of knowledge construction [32]. When a textbook incorporates different cultures, it may help students to construct images of the places where the language is spoken and to forecast key aspects of culture that they may study in greater depth in the future when their language abilities increase [23]. In addition to incorporating cultural elements in textbooks [25] recommends authors of language textbooks to incorporate well-known characters from different areas of the world to allow students grasp the six teachable pillars of character" (trustworthiness, respect, responsibility, fairness, caring and citizenship). But, the textbook under review did not incorporate well-known characters from different parts of the world.

\subsection{Supporting Personal Interpretation of Experience and Use of Authentic Learning Materials}

In preparing language textbooks, constructivists suggest incorporating elements which allow students to be conscious about what is happening in their environment, reflect their culture and identity, and use multiple perspectives of language construction [29]. Similarly, the textbook under review, incorporated a number of pictures which makes students to feel that they are learning about real life. Majority of the images in the textbook show: playing children, swimming, students at different school activities (reading, writing, working in group etc.), playing kids, children helping their family, individuals at shopping, individuals engaged in different indoor and outdoor activities and the like. In this way the images and pictures in the textbook represented part of real life and made the book to have lifelike situation. Additionally, the activities and reading passages in the textbook under review have features which allow students to talk about themselves, their social life and their environment. These things, allow learners to make personal interpretation of their own experience. Regardless, of incorporating different contents which provide learners opportunity of interpreting their own experience, the textbook under review has limitation in incorporating elements which encourage use of authentic learning materials. Constructivists believe that, use of authentic learning materials such as newspapers, magazines, articles, songs, web pages, radio \& TV broadcasts, films, leaflets, flyers and posters contribute to make language learning realistic [12]. In contrast, even though, English for Ethiopia grade 5 teacher's guidebook order the teachers to use authentic learning materials in classrooms and encourage students to use English language outside classroom. The textbook under review did not incorporate activities which require use of authentic learning materials or provide specific activity and/or direction which encourage/support students to use authentic language learning materials and practice English language outside classrooms.

\subsection{Enhancing Critical Thinking, Creative Thinking and Problem Solving Skills}

Constructivists suggest that, language textbooks should incorporate activities which enhance learners' critical thinking skill, creative thinking and problem solving [17]. [17] argue that these skills will be enhanced when lessons and subjects: begin with questions, create foundations i.e., provide for students' review of related information, consult the classics, include content which help students to develop interdisciplinary knowledge, utilize peer groups, provide sequential activities, prepare goal free problems/activities, facilitate roleplaying, translate thoughts to pictures, prioritize critical thinking and change misconceptions. In this regard, the textbook under review incorporated majority of elements suggested by [17]. Different activities presented in the textbook have features of enhancing students critical, creative and problem solving skills. For instance, tasks at the beginning of each unit, contents from disciplines, group activities and role plays challenge students and motivate them to seek deep understanding, collaborate with each other and develop multi-disciplinary knowledge. Additionally, vocabularies attached as appendix of the book also have a function of serving as additional source of motivation for students to search more sources of knowledge and consult classics. On the other hand, though the textbook under review incorporated many elements which promote critical thinking, creative thinking and problem solving skill, it did not incorporate activities which require translation of texts into pictures.

\section{Conclusion and Recommendation}

\subsection{Conclusion}

From the findings of present review, it is possible to say 
that English for Ethiopia grade 5 textbook is prepared in line with constructivism principles. Additionally, the findings of the present review reveal that:

English for Ethiopia grade 5 textbook course syllabus and the guidebook suggest EFL teachers to play role of facilitator, guide, coach and scaffolding; and suggest the teachers to implement active learning approach. But, specific objectives stated in the textbook do not consult and allow learners in forming topics.

A number of activities incorporated in English for Ethiopia grade 5 textbook promote personal construction of knowledge, active learning and collaboration.

English for Ethiopia grade 5 textbook has a number of elements which: make grade 5 EFL learning realistic, make learning situations relevant and activate learners' prior knowledge.

English for Ethiopia grade 5 textbook incorporated different concepts from different disciplines and integrate the four macro-language skills. This contributes for multiple exploration of knowledge and meaning making.

English for Ethiopia grade 5 textbook incorporated contents and activities which help students to have interdisciplinary knowledge, utilize peer groups, provide sequential activities, facilitate roleplaying and change misconceptions. These contents and activities have feature of enhancing learners' critical thinking, creative thinking and problem solving skills.

Even though majority of tasks in English for Ethiopia grade 5 textbook are designed in line with constructivism principles it has limitations in terms of:

1. Incorporating self-assessment questions which will positively contribute in enhancing learners' independent learning, self-analysis, self-regulation and selfawareness.

2. Allocating proportional time for units. The course syllabus did not consider the width of chapters and diversity of activities while seating time for lessons in the textbook.

3. Incorporating activities which encourage use of authentic learning materials.

\subsection{Recommendation}

From the review made to enhance effectiveness of Ethiopian grade 5 English language education, the present researcher forwarded the following points as recommendation: instructional approaches of English language education and the textbooks need further investigation. Authors of English for Ethiopia textbooks should review the textbooks and consider providing objectives which promote active through presenting objective which give learners autonomy of negotiating on learning objectives; rather than allocating uniform time for all units in the textbook proportional time should be allocated for units based on width of the lessons; the textbook should incorporate elements which encourage use of authentic reading materials and use of English language outside classroom; and, adequate self-assessment questions with answer keys need to be included in the textbook.

\section{References}

[1] Brown, H. D. (Ed.). (2006). Principles of language learning and teaching.

[2] Chapelle, C. A. (2016). The Significance of Culture in Language Teaching. In Teaching Culture in Introductory Foreign Language Textbooks (pp. 1-35). Palgrave Macmillan, London.

[3] Cook, V. J. (1983). What should language teaching be about? ELT Journal, 37 (3), 229-234.

[4] Crockett (2018). 12 Strong Strategies for Effectively Teaching Critical Thinking Skills. Retrieved from: https://globaldigitalcitizen.org/author/leecrockettme-com

[5] Davies C A., (2015). How Do You Make Learning Fun to Increase Students' Success? Retrieved from: https://resumesfor-teachers.com/blog/author/candace/

[6] Dereje, N. B. (2012). Primary English as a Foreign Language (EFL) Teaching in Ethiopia: Policy and Practice (Doctoral dissertation, Addis Ababa University).

[7] Ebersöhn, L., \& Eloff, I. (Eds.). (2004). Keys to educational psychology. Juta and Company Ltd.

[8] Eggen, P., \& Kauchak, D. (Eds.). (2010). Educational Psychology: Windows on Classrooms. 8th. Upper Saddle River, NJ: Pearson.

[9] Gettinger, M. (1985). Time allocated and time spent relative to time needed for learning as determinants of achievement. Journal of Educational Psychology, 77 (1), 3.

[10] Greatschools. (2016). Character education: as important as academics? Retrieved from: https://www.greatschools.org/gk/articles/the-value-ofcharacter-education/

[11] Guo, S. C. (2012). Using Authentic Materials for Extensive Reading to Promote English Proficiency. English Language Teaching, 5 (8), 196-206.

[12] Hinkel, E. (2010). Integrating the Four Skills: Current and Historical Perspectives.

[13] Kapur, V. (2017). Understanding constructivism in the second language learning context. Scholarly Research Journal for Humanity Science \& English Language, 5 (25), 7061-7080.

[14] Kasmaienezhadfard, S., Pourrajab, M., \& Rabbani, M. (2015). Effects of Pictures in Textbooks on Students' Creativity.

[15] Long, M. (2000). The psychology of education. New York, NY: Routledge.

[16] Mahoney (2002). Constructivism and positive psychology. In C. R. Snyder, \& S. J. Lopez, (Ed.), Handbook of positive psychology. New York, NY: Oxford University Press.

[17] Murphy, E. (1997). Characteristics of Constructivist Learning $\&$ Teaching. Available from http://www.ucs.mun.ca/ emurphy/stemnet/cle3.html

[18] Pritchard, A., \& Woollard, J. (2010). Psychology in the Classroom: Constructivism and Social Learning. New York, NY: Routledge. 
[19] Pressley, M. (2000). What should comprehension instruction be the instruction of? In M. L. Kamil, P. B. Mosenthal, P. D. Pearson, \& R. Barr (Eds.), Handbook of reading research (pp. 545-562). Lawrence Erlbaum Associates, Inc.

[20] Pressley, M. \& McCormick, C. B. (Eds.). (1995). Advanced Educational Psychology. For Educators, Researchers, and Policymakers. HarperCollisCollegePublishers.

[21] Rabago, O. D., (2014). Constructivism: A Key to Learn the English Language Effectively. NCT, Nizwa.

[22] Ramirez, G. M. (2012). Usage of Multimedia Visual Aids in the English Language Classroom: A Case Study at Margarita Salas Secondary School (Majadahonda). Unpublished Masters Dissertation). Matritensis University, Spain.

[23] Redigan, S. (2014). Constructivism and English Language Arts: Creating Inclusive and Relevant Curricula. Retrieved from $\mathrm{http}: / /$ sydneyredigan.com/wpcontent/uploads/2014/07/Constructivism-and-EnglishLanguage-Arts.pdf

[24] Richey, R. C., Klein, J. D., \& Tracey, M. W. (2011). The instructional design knowledge base: Theory, research, and practice. Routledge.

[25] Salkind, N. J. (Eds.). (2008). Encyclopedia of educational psychology. California: Sage Publications.
[26] Schaub, S. (2012). Acquiring Second-Languages Through Constructivist and Communicative Approaches in Literacy Collaborative Schools. Literacy Collaborative at Ohio University.

[27] Sehibi, M., \& Mellouk, Y. (2015). Investigating the Culture Component in EFL Textbooks: Case of 1st Year secondary school, Tlemcen (Doctoral dissertation).

[28] Shin, J. K. (2007). Developing dynamic units for EFL. In English Teaching Forum (Vol. 45, No. 2, pp. 2-8). US Department of State. Bureau of Educational and Cultural Affairs, Office of English Language Programs, SA-5, 2200 C Street NW 4th Floor, Washington, DC 20037.

[29] Van Craeynest, F. (2015). Gender representations in EFL textbooks: a quantitative and qualitative content analysis.

[30] Wijayanti, D. N. (2013). Constructivism Theory of Language Teaching and Learning. Retrieved from https://mydreamarea.wordpress.com/2013/01/05/constructivis $\mathrm{m}$-theory-of-language-teaching-and-learning/

[31] Wirtenberg, J., Murez, R., \& Alspektor, R. A. (1980). Characters in textbooks: A review of the literature (Vol. 62). US Commission on Civil Rights.

[32] Ültanir, E. (2012). An Epistemologic Glance at the Constructivist Approach: Constructivist Learning in Dewey, Piaget, and Montessori. 